\title{
Pioderma gangrenoso como primeira manifestação de doença sistémica
}

\section{Gangrenous pyoderma as a first expression of systemic disease}

Doente de 24 anos, assintomática do ponto de vista gastrointestinal, em que o diagnóstico de Doença de Chron (DC) ocorreu na sequência da investigação das doenças associadas ao Pioderma Gangrenoso (PG).0 tratamento dirigido à DC melhora, habitualmente, o PG. Neste caso, optou-se pela corticoterapia sistémica, com resolução completa da dermatose. Verificou-se melhoria parcial das lesões intestinais, pelo que se optou por iniciar azatioprina $150 \mathrm{mg} / \mathrm{dia}$, para melhor controlo da DC.

\section{Bibliografia}

1. Pioderma gangrenosum, www.uptodate.com [Jun 2013].

2. Bolognia JL, Jorizzo JL, Rapini RP. Pyoderma gangrenosum. Dermatology. 2003;1:415-418.

3. Ahronowitz I, Harp J, Shinkai K. Etiology and management of pyoderma gangrenosum: a comprehensive review. Am J Clin Dermatol. 2012;13(3):191-211.

4. Callen JP. Pyoderma gangrenosum. Lancet. 1998;351:581-5.

\section{Diagnóstico:}

\section{Pioderma gangrenos} associado a Doença de Chron

Sara Estrela ${ }^{1}$, Patrícia Santos ${ }^{2}$

${ }^{1}$ Centro Hospitalar do Médio Tejo ${ }^{2}$ Hospital Divino Espirito Santo)

Correspondencia: saraestrela2@gmail.com

Como citar este artículo: Estrela $S$, Santos $P$

Pioderma gangrenos associado a Doença de Chron. Galicia Clin 2016; 77 (3): 148 Recibido: 29/12/15; Aceptado: 03/02/16

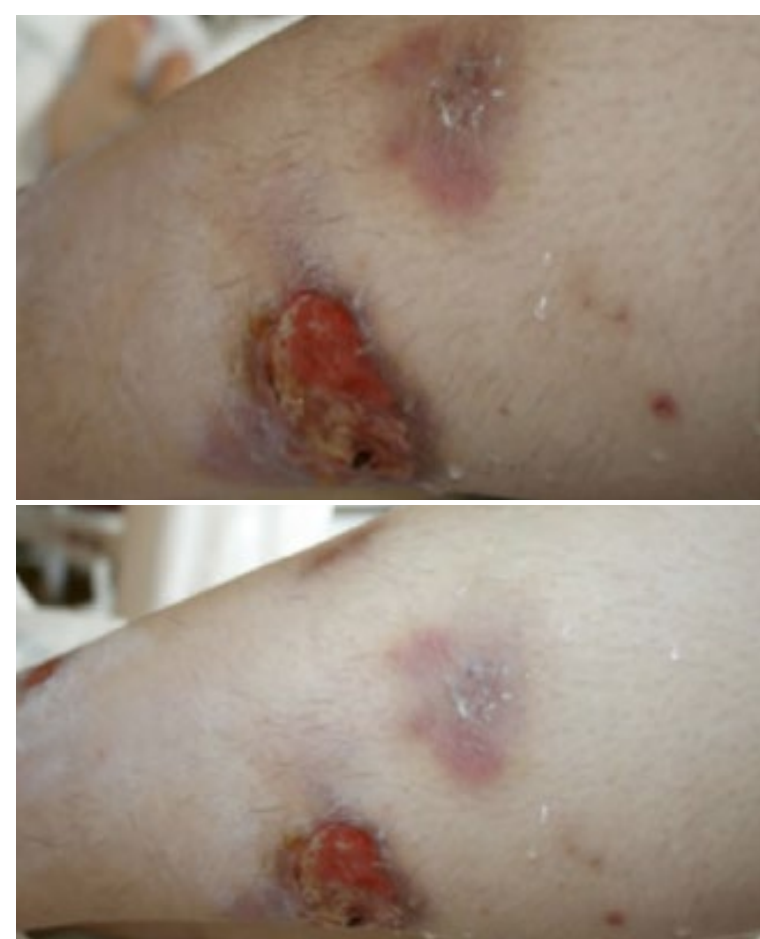

Figura 2
